\title{
SUSTAINABLE URBAN MOBILITY PLANNING DEVELOPMENT PRECONDITIONS: GOVERNANCE SYSTEM APPROACH
}

\author{
Zanda Krukle, Liga Biezina, Raimonds Ernsteins \\ University of Latvia, Latvia \\ zanda.krukle@inbox.lv, liga.biezina@lu.lv, raimonds.ernsteins@lu.lv
}

\begin{abstract}
Sustainable mobility means keeping the ability of people to travel and supply goods in a way that balances environmental and socio-economic aspects and aims at the reducing of negative impacts on environment. The aim of this research is to study how the mobility governance is built and particularly governed in sustainability understanding aspects in urban municipalities in Latvia, using the case of Valmiera town. In the scope of this step-by-step complementary study different transportation modes have been studied with special emphasis put on the necessary application of socio-ecological system and stakeholder participation principles, and, particularly, governance instruments design and application - all six main groups of instruments and their complementary application for urban sustainable mobility. The research has been carried out employing both research-and-development framework and case study research methods, allowing to provide integrative contextual analysis of the particular sustainable mobility subject in the chosen urban area, including document analysis, semi-structured deep interviews with each stakeholder group representatives, household proenvironmental behaviour questionnaire and structured observations. Also, the development planning process was studied and in particular the case of Valmiera Transport development program development and its impact on environment assessment. The research allowed drawing conclusions on the urban sustainable mobility governance aspects in Valmiera and for Latvia municipalities in general. The future developments should include the joint action plan that would foresee the cooperation and implementation of integrative action between the different transport sectors, policy makers, and relevant authorities, as well as sectorial and inter-sectorial policies planning. These documents should be based not only on detailed and professional evaluation of the transportation aspects in the municipality, but to be based on social-ecological systems governance understanding and application, subsequently, including also on evaluation and modelling of transport related environmental issues such as air pollution and environmental noise etc. in order to manage basic challenge for sector-based planning system and special integration of transport planning and environmental planning.
\end{abstract}

Keywords: mobility, sustainability, environmental governance, Latvia.

\section{Introduction}

Mobility is a multidimensional concept and an integral and important part of the everyday life that ensures the delivery of goods and human travel from one place to the other, enabling social, cultural, political and economic activities to take place. It expresses both, the potential for the transportation and travel as well as the actual movement itself [1]. Meanwhile, transport, especially in urban environment, nowadays is one of the main environmental stressors and along with housing and food is considered to be one of the most important consumption aspects of the households [2]. The environmental and climate impacts of the transport sectors include increased temperature, greenhouse gas emissions, air and noise pollution, etc. It together with health and transport safety aspects may impact urban quality and wellbeing of inhabitants. The transport has also an important cultural, social and economic role of the development of the local governments, including the development of industrial activities, fair distribution of the services to all inhabitants, etc. Therefore, mobility should be developed in a sustainable way that takes into account environmental and socio-economic aspects when ensuring the possibility to travel and supply stocks [3-4]. Understanding that the urban environment is a complex, complimentary, integrated social, ecological and economical system, calls not only for the sustainable urban and transport conceptualisation, formulation, but also actions in all governance/policy phases [3;5] .

To develop sustainable mobility - to ensure the ability to transport stock and travel in a way that makes balance between social, economic and environmental perspectives, including the target on the reducing of negative impacts on environment (i.e., ecosystems, energy sector, etc.) and socioeconomic development (i.e., costs, holistic health, safety, etc.) [3-4], a broad spectrum of transport related initiatives should be used to ensure the necessary results. However, the decisions and action in this regard are not easy, as it must respect both parts - environmental externalities and economic progress, and a successful policy aim to achieve results, but also it must be quite realistic on what can be attained not hindering further development [6]. 
The EU transport policy [7-8] in this respect foresees the improvements regarding environmental and climate aspects, transport security and service quality, transport related innovations and research policies, upgrading of the infrastructure and mainly the implementation of the integrative and complex sustainable transport and integrated urban mobility principles. Sustainable mobility means that the people's rights to transportation are respected, social (e.g. safety and equity) and economic accessibility is improved, and environmental pollution and its impact of the holistic health and people wellbeing are reduced. The European Commission highlights the impacts of such policies and measures on the provision of adequate, fair and secure mobility solutions for all citizens and to the achievement of the EU targets for reducing carbon dioxide emissions, noise, air pollution and traffic accidents [7-8]. This clearly demonstrates the impacts and importance of social, economic, environmental, cultural, spatial and governing factors that must be taken into account when planning sustainable and integrated urban mobility systems, and that are reflected in the social-ecological system approach.

There are three main strategies on how to ensure transition towards more sustainable transportation. The first of them is the reduction or avoiding unnecessary transport. The second is modal change or shifting necessary transport from environmentally harmful to more environmentally friendly modes. The third one is increasing of eco-efficiency or improving the environmental performance of all modes of transport [9-11]. Similar strategical approach is described by D.Bannister, who in addition distinguishes also the fourth strategy - reduction of trip lengths [12]. To implement these strategies (also taking into account in the social-ecological system approach), a combination of many integrative and sectoral activities should be used. This includes the further development of sharing and circular economy, promotion of remote work and e-services, development of integrated intermodal and/or communal transport policy by combined use of the various transport modalities, further optimisation of the transport services, innovations, carbon reduction measures in the transport sector (including eco-labelling, eco-driving, "zero" urban logistics for freight vehicles), promotion of sustainable transport solution (including collective transport, shared vehicle use, rental and leasing services), addressing the lack of services for disabled people, promoting the use of low emission transport (including public transport), providing for a long-term parking policy, improvement of the transport infrastructure and land use policies, development of close-to-citizens services etc. This all should be developed in accordance to the national and local urban mobility plans that are based on the results of systemic audits of their transport systems and the society opinions [7-12].

Despite the general knowledge on sustainable mobility and about activities that could help to implement it in the municipalities, in real life conditions it is hard to efficiently implement the sustainable mobility concept due to many spatial, administrative and political aspects and complex policy programming, planning and implementation practice [13].

Therefore, the sustainable transport paradigm is a purposeful transport system that is implemented with a range of policy instrumentalities and that has the support of all stakeholders [12]. This suggests that the sustainable mobility should be governed taking into account the whole set of instruments or tools: political and legislative, planning, administrative and institutional, infrastructure and technological, as well as communication instruments at all stages of the governance (policy) cycle "5P" (i.e. P1 - problem analysis, P2 -policy formulation, P3 - planning, P4 - program implementation, P5 - process monitoring stages). It is also necessary to take into account the needs and views of all the main management target groups - national authorities, local government, business sector, citizens and mediators (non-governmental organisations, media, education and science/experts) - not only in regard to the full context of mobility itself, but also on its impacts on social-ecological systems [5;14;15]. D. Bannester researches especially highlight the importance of the stakeholder involvement in the discussion, decision-making and implementation processes, because this forms the society acceptance of the sustainable mobility concept [12].

As it is mentioned above, for the implementation of sustainable mobility principles, long-term urban mobility strategies and mobility plans are advised to be developed. The development of these plans, including self-assessment and audit, is considered to be the best practice for municipal mobility governance. These plans should define aims and objectives and set long-term vision, include evaluation of existing situation and the development of further action plan. It should take into account all governance instruments and need to ensure balanced (in social, economic and ecological aspects) 
and integrated mobility content (public transport, cycling, private motorized transport, inter-modality, logistics, mobility governance) [16].

Transport and especially suitable transport issues are topical in the Central and East Europe countries, where the main concern related to it is a substantial increase in the demand for transportation [17]. Nonetheless, the Central and East Europe regions have a "starting advantage", when it comes to transport sustainability compared to the other EU member states [17]. In order to move towards better transport and to achieve the objectives of the European transport policy, in particular with regard to sustainable mobility, the Latvian transport policy and the National Sustainable Development Plan foresee the development of sustainable public transport and comodality, ensuring better access and accessibility, as well as the development of a convenient and integrated public transport system. Regarding the local planning level in Latvia, sustainable mobility practices are still rather underdeveloped, for example, in Latvia currently only some municipalities have developed urban mobility plans. The most recent urban mobility plan that is a part of the transportation thematic planning was developed in Valmiera town, what is one of the regional development centres in Latvia, even having less than 25000 inhabitants.

Therefore, the purpose of this research as the research-and-development project - to study how the sustainable and integrative urban mobility principles have been implemented and what kind of mobility governance has been established and functioning, and which aspects in particular should be taken into account for the development of sustainable mobility strategies and governance practice - the authors provided sustainable mobility complex case study research in Valmiera town and participated in and evaluated the content and development process of the Valmiera Transport development strategy.

\section{Materials and methods}

\subsection{Research area}

The research was carried out in Valmiera city that is one of the major cities of national significance and is one of main development centres with the area of 19,35 km2 and 23248 inhabitants. Valmiera city is located 50km from Estonian - Latvian border and $107 \mathrm{~km}$ from the capital Riga. For internal travel in the city people walk, cycle, use private means of motorized transport (cars, motorcycles), as well as taxi and public bus services. For intercity mobility couch and train services are available. Valmiera city is of industrial characteristic and there are many lorries and other heavy machinery operating. Meanwhile the city has declared that it respects social, economic and environmental interests. Valmiera is also one of the two municipalities in Latvia that has adopted the voluntary environmental policy declaration (2015) [18] that among other things aims at reducing emissions from the transport sector, promoting cycling and development of its infrastructure.

Valmiera city was chosen for the case study because of its national importance, socio-economical characteristics, its aim to become a sustainable city, as well as the recent development of the urban transport strategy. Valmiera city was also one of three research areas that were included in the National Research Programme "Innovation and sustainable development: Latvia's post-crisis experience in a global context (SUSTINNO)" project No.4. "Environmental Diversity and Sustainable Governance" (hereinafter - SUSTINNO project) and was open to the cooperation for environmental and transport management studies.

\subsection{Research methods and methodology}

The research was designed in the way that would allow to study how the sustainable, integrative urban mobility can be planned in the systematic way and which aspects should be taken into account for the development of sustainable mobility strategies. Therefore, the research was carried out using the research and development, case study and participatory action research methods, as it allowed not only provide sectoral and inter-sectoral analysis of the Valmiera mobility case, but also to provide policy suggestions to the municipality and other stakeholder groups, as well as a possibility for the researchers and society to work together to scrutinize the situation and provide solutions for the sustainable mobility development through the participation in the transport strategy in Valmiera. During the research process the content of the strategy and the participation process were analysed, 
taking into account the previous studies on the mobility in Valmiera of these authors. The research consisted of two main parts - the research on sustainable mobility, including cycling, and the participatory action study.

- The first part - the research on sustainable mobility, including cycling:

The researches on mobility issues in Valmiera have been carried out in Valmiera during 2017 - 2018 and are described in the previous authors' research papers. The researches were carried out employing the case study research method, aimed at the scrutinization of the existing situation and discovering solutions to problems in the field of sustainable mobility and cycling in Valmiera. The research was also based in the research-and-development framework as it included policy recommendations for the municipality and other stakeholder groups. As the research was carried out on a long term basis (from 2017-2019), it allowed concluding on the changes and adjust the further recommendations.

Within the study the sustainable mobility and cycling in Valmiera were analysed through the prism of the social-ecological system approach, looking at the mobility and its impacts from the social, economic, environmental, cultural, spatial and governance point of views. The research also explored the use of six governance instruments (planning, political and legislative, administrative and institutional, economic and financial, infrastructure and technical, as well as communication instruments) within all stages of the "5P" governance cycle (problem analysis, policy formulation, planning, program implementation and process monitoring stages). This combined and integrative approach allowed to provide systemic audit and conclude on the strengths and weaknesses, opportunities and threats, as well as to propose further improvements.

The study included: the analysis data from a representative public pro-environmental behaviour survey carried out in 2016 within the framework of the SUSTINNO project, analysis of the main municipal level planning documents, on-the-site observations and testing of transport infrastructure, semi-structured deep interviews with the representatives of eight main stakeholder groups, 112 express interviews on the streets with Valmiera inhabitants, using random selection approach and 10 in depth, semi - structured interviews with households. In order to verify the data obtained in local surveys, the data of the nationally representative public opinion survey $(n=1009)$ carried out previously also within the SUSTINNO project and data from annual municipal resident questionnaires (total $n=2570$ ) were used.

- The second part - the participation action research during the process of the development of the transport strategy:

Based on the above described case of sustainable mobility in Valmiera, SWOT analysis was performed and conclusions and improvement proposals were sent to the municipality (August, 2018) with an aim to support the municipality during the preparation stage of the transport strategy. The authors also participated in the public consultation of the Valmiera transport strategy (November, 2018), by scrutinizing Valmiera transport strategy and commenting on the strategical document based on their professional knowledge and conclusions from the previous case studies, taking into account the prism of the social-ecological system approach, the complex and integrative use of governance instruments, within all stages of the " $5 \mathrm{P}$ " governance cycle and the needs of stakeholders.

The authors also participated in the public hearing meeting (November, 2018), as well as repeatedly during the public consultation process submitted the results of the case studies and all documents of the analysis done.

\section{Results of performed studies}

National and local sociological surveys on Valmiera sustainable mobility patterns and its comparison to other cities (such as Liepaja and Riga) and national data analysis showed that the most critical factors impacting the residents' behavior are not only the transport infrastructure, but most importantly - a lack of habit, social status, laziness, need to sacrifice conveniences. This is well shown by statistical data that prove that Valmiera has a high private car usage rate - over $65 \%$. Also $44 \%$ of residents in Valmiera, never use public transport, because only two-thirds of residents are satisfied 
with the public transport system in Valmiera and mainly complain about the complexity of the routes and the slow movement of buses. Residents of small Latvian cities, like Valmiera and Liepaja, on average drive short distances, for instance, quarter residents drive as little as $10 \mathrm{~km}$ per week. This shows that most of the respondents could be subjected to modal change; however, the promotion of the modal change and changing of the habits is quite a complicated task, especially, if there are no other motivating mechanisms and instruments in place.

The more detailed sectorial evaluation on the cycling aspects in Valmiera city showed that the cycling infrastructure, in general, is considered to be in good quality, though, the cycling routes are fragmented and not always fully comply with the standards, especially regarding their conductivity, safety. There are also issues with bicycle parking and repair options. Apart from the technical inspection results, the survey concluded on the need for appropriate cycling policy with clear objectives, well-defined tasks and a whole set of governance instruments involved at every stage of the " $5 \mathrm{P}$ " model is needed for successful, sustainable, integrative and inclusive cycling development, including the need for the development of the cycling governance concept.

A study on sustainable mobility management showed that there is a whole set of governance instruments in place to develop and promote sustainable mobility in the city. However, taking into account the social survey data and primary sector issues identified during the Valmiera case studies (please, see the summary of the results in Table1), it was concluded that the municipality is willing and planning to move towards sustainable mobility and it has prepared municipal planning documents that include sustainable transport (for instance, green declaration), but there still is a need for further complementary policy actions to be planned and implemented. They include a need to raise environmental awareness for Valmiera residents, to increase their participation, further development of the infrastructure that could support sustainable mobility in Valmiera, re-evaluation of the use of administrative and economic instruments, usage of transport impact modeling and assessment and practical appliance of the socio-ecological system approach.

Table 1

Main sustainable mobility sector issues (by the type of governance instruments) according to the previous study results

\begin{tabular}{|l|l|}
\hline \multicolumn{1}{|c|}{ Instrument } & \multicolumn{1}{c|}{ Issues } \\
\hline Economic and financial & Need for financial initiatives (for example, parking fees) \\
\hline Administrative and institutional & Need for more stringent administrative regulations, supervision \\
\hline Political and legislative & Initiatives for further moves towards sustainable transport \\
\hline Planning & $\begin{array}{l}\text { No sustainable transport concept has been developed so far } \\
\text { (2017), including bicycle policy }\end{array}$ \\
\cline { 2 - 3 } & $\begin{array}{l}\text { When designing documents, the content of a particular sector is } \\
\text { not always fully analysed and included in an integrative way, } \\
\text { thus also not fully evaluating and taking into account the social- } \\
\text { ecological system approach and its sectors }\end{array}$ \\
\hline Infrastructure & $\begin{array}{l}\text { The continuity, safety, and convenience of the cycling network } \\
\text { are not yet fully ensured and further upgrade and extension of } \\
\text { the bicycle transport infrastructure is needed }\end{array}$ \\
\cline { 2 - 3 } The further economic development might require the strategic, \\
but expensive transport infrastructure, such as new a bridge, \\
bypass
\end{tabular}




\section{Results and discussion}

Complementary compiling and analyzing the results of the performed studies in an integrative way, the authors conclude that Valmiera municipality in principle recognizes the need for further development of urban mobility that would take into account social, economic and environmental aspects, including the need to shift towards sustainability, also taking into account its green declaration. However, the research provided suggestions for further sectorial and multi-sectoral improvements that might be useful for more dedicated transition to sustainable municipal governance. For instance, municipal planning documents mostly describe transport mostly from the sector perspective, therefore purposeful appliance of the socio-ecological system approach that requires integrative evaluation of transport from the social, economic, environmental, cultural, spatial and governance point of view would help better promote positive aspects, tackle bottlenecks and coordinate actions in an intersectoral way. The planning documents also currently do not explicitly evaluate and model transport-related environmental issues, such as air pollution and environmental noise, that is the best practice from other countries and would show further intentions in sustainability and environmental aspects.

The research on the people behaviour that was done through the analysis of documents, statistical data and sociological surveys also showed a high dependence on private cars, low usage of public transport and rather unsustainable mobility habits of the population, that require not only awareness rising, but also systemic changes, such as more dedicated appliance of political, administrative and planning issues to reduce the need to travel and promote the change in the dwellers' behaviour. The information on recent developments, health and education benefits should be spread to the society that would correspond well to the socio-ecological system approach. Currently, Valmiera municipality has further intentions for upscaling of vehicle-related infrastructure due to industrial development in the town and also due to resident demands (especially for parking lots in the centre) through the "bottom up" approach and taking into account the need of pragmatic municipal governance. There is a risk that these incentives might bring adverse effect on the population habits. However, municipality tries to compensate it by developing attractive and convenient public outdoor space (that is family and environmentally friendly and promotes physical activities), to promote other means of transport and to create the infrastructure for sustainable mobility modes. This, for instance, includes an expansion and upgrading of the cycling infrastructure. The cycling infrastructure, by the assessment done through the previous studies, is of good quality; however, further development of the routes and their length are needed. Also, the amount and quality of the system elements (such as bike stands, signs, etc.), better network continuity, directness, attractiveness, and also safety and comfort for the travellers should be improved. The municipality, however, should also accurately evaluate whether the chosen "soft" approach for the transition to sustainable mobility brings the desired benefits and helps reach the targets (that are set in the green declaration of the city). The regular verification of transition speed and success would be in accordance with the research and development approach that allows to test, adjust the actions and propose further improvements.

There is available the basic set of main management tools in the municipality to promote urban mobility in Valmiera; however, certain tools, such as infrastructure and technology tools, are used more explicitly than the others, being not satisfactory, neither developed, nor applied, especially in complementary matter. To ensure smart, effective, sustainable, environmentally friendly and safe mobility, further development of the mobility governance system (actually starting from the system itself) and especially complementary use of all instruments at all stages of the policy cycle are needed.

Therefore, the authors have come to the conclusion that, despite the fact that the main management elements in place, but still not all preconditions known and used, the sustainable mobility concept is not yet really developed systematically, strategically and interactively. To ensure that, a long-term, sustainable transport strategy that would include also the cycling strategy would be needed. This issue was also recognized by the authors in the case studies [14-15], when the authors concluded that municipal planning documents should contain a complex and integrative action plan that would foresee dedicated municipality plans for the implementation of the sustainable mobility concept. This plan should include the integrative urban mobility design that foresees the complimentary use of different transport modes, takes into account three main sustainable mobility categories, respects the views of all stakeholders, as well takes into account the socio-ecological approach, the evaluation of 
social (health, safety, social problems, culture aspects etc.), economic (fares, tax, fines, congestion charges, ability to pay, etc.) and environment issues, and their governance issues as well. It also should include the appraisal and modelling of transport related environmental issues, such as air and environmental noise pollution according to the best practice approach.

In 2017-2018 the municipality (with the help of a consulting company) developed the municipal Transportation strategy. The strategy evaluates the existing Valmiera city transport infrastructure, identifies the main problems and proposes a concept for further transport development. The strategy is a part of the thematic planning of Valmiera town and mostly focuses on the infrastructure.

Within this research the authors participated in the process of the development of the strategy, provided information on the previous authors' case studies in Valmiera town, in particular, on the management instruments, stakeholder groups, "5P" governance cycle as well as the socio-ecological approach. The authors also perused the transportation strategy in great details and proposed improvements of the strategy content through the public consultation process. The scrutinization of the strategy showed that the strategy includes only a part of the necessary integrative components - it lacks explicate evaluation of the actual and potential appliance of the whole set of management instruments, the analysis and inclusion of the views of all stakeholder groups, as well as the socioecological approach.

The analysis of the strategy showed that it lacks full and in-depth assessment of the stakeholder views. Without population surveys on the target group (pedestrians, cyclists, motorists) views, their characteristics, desirable changes, most used routes, motivation to use one or the other means of the transportation, reasons for the high dependence on private motorised vehicles and low usage of public transport it is impossible to develop a sustainable transport infrastructure development concept that would be purposeful and would bring the best benefits. Important information about environmental noise and other types of pollution and population survey results on the effects on public were also missing. All these aspects, however, are particularly important for the development of the transport concept. Only full information of these reasons can show the direction of the best and most appropriate solutions.

The strategy did not provide full assessment and proposals for the development of the integrative and comprehensive sustainable urban mobility concept in Valmiera city. It also included some elements, such as the information of priority modes of transport, which corresponds well to the concept replacing least sustainable transport mode with another. However, as the strategy still foresees the expansion of motorisation, it might prevent adequate implementation of the desirable sustainable mobility concept. The other two basic modal change concepts - the reduction of unsustainable patterns and efficiency improvement - have not been analysed at all. The interconnection of modalities was analysed in a very limited amount.

The strategy, though, provides a quantitative evaluation and proposals for infrastructural development. Nevertheless, it should concentrate also on the development of qualitative, interconnected and integrative upgrade of the system, taking into account full and complimentary set of management instruments that would foresee the best combinations and alternative scenarios and would lead to the sustainable urban mobility goal. The document currently includes some aspects and elements rather than a full scope of the governance elements, instruments and approaches.

When analysing the strategy from the policy cycle point of view, it includes the situation audit, with an exemption of sociological surveys. It has an action plan, including potential project ideas, however, the action plan should be better linked to the municipal budget, thus showing the municipal ability to implement it. The document should better describe the monitoring framework, so that it is in accordance with the basic principles of strategic planning - the key indicators should be related to the objectives of the concept, but the goal should be measurable.

The strategy initially did not include the analysis of the major strategic municipal planning documents, such as Valmiera Environmental Declaration and other environmental planning documents. The environmental impact assessment report only partially (and formally) contains the information required by the legislation and lacks proper evaluation and modelling of important environmental stressors and pollutants, such as noise and air pollution. When planning the development of urban transport systems, the modelling of transport emission dispersion and noise 
pollution is absolutely necessary, as that would help properly plan not only abating measures, such as traffic calming measures, street greening, anti-noise measures, but also take into account the complexity and interactivity of these impacts not only on environment per se, but also the socioeconomic aspect and economics (such as annoyance, lost life years due to these impacts on public health, medicine costs, willingness to pay, abatement measures, etc.). Besides non-detailed environmental and socio-economic impact analysis (such as mobility impacts on the employment, etc.), the strategy leaves out also cultural aspects, thus showing that the socio-ecological approach is not fully respected.

Nevertheless, the authors assess that Valmiera has a good potential of becoming the first Latvian municipality that integrates sustainable mobility principles in the municipal planning and implements it purposefully in a strategic, complementary, integrative, focused way, taking into account the socioecological approach, mobility management strategies, set of management instruments at all stages of the policy cycle, thus ensuring not only sustainable, but also smart, effective, fair and safe mobility. For suitable urban mobility to work fruitfully, it should be developed on the evaluations, modelling and sociological data. It should be purposefully adopted as a complex, integrative and complementary concept that consists of a fit-to-purpose and tailor-made set of actions rather than segregated, stand alone actions. It also must have a political support to be implemented. It should also be monitored and re-assessed based on research-and development framework also further.

No question, that sustainable mobility should be further integrated in other municipality mandatory and voluntary documents and actions, including the environmental communication strategy that is about to be developed, however, it shall be clear from very beginning that this also still will be a challenge.

\section{Conclusions}

1. The municipal case study has confirmed that in Valmiera as well as in other municipal territories in Latvia known from other mobility type studies do exist several sustainable mobility elements in place already, but purposeful and systemic structuring and complex governing towards sustainable urban mobility is still a serious challenge mainly due to general administrative (planning) capacities and understanding possessed as well as the existing/inherited sector type (e.g. social, education, culture etc. sectors planning), but not the system governance (planning) type problematics being the basic precondition for cross-sectorial issues governance (planning).

2. In order to design and implement a sustainable urban mobility municipal action frame, it is advisable that municipalities should not only develop the concept on how to provide transition towards sustainable urban mobility, but particularly, and, first of all, also elaborate clear outline towards the municipal mobility governance system establishment as the next pre-condition - either an integrative system as legally prescribed collaboration between different municipal departments and institutions, or established as a separate administrative mobility governance branch, depending on traditions and possibilities etc. at any particular municipality.

3. Also there is a mandatory precondition to perform the necessary mobility (governance) system analysis as of the socio-ecological-governance system as a basic pre-planning activity, starting from the existing situation audit, including particularly often not fully done at municipal level, the systemic analysis of all transportation types used/planned in the municipality and in their complementarity all their impacts etc.

4. This municipal mobility governance system development shall include all three main governance dimensions as the main precondition. The governance segments - real involvement of the main stakeholders and their groupings (municipal, governmental, corporate, households/inhabitants and social mediators), but importantly, all this is to be done for the whole policy/governance cycle as from problem analysis till policy implementation supervision. Following, there is to be elaborated the governance process (cycle governance) and particularly complementary development and use of all these six main types of the governance instruments. The governance content - socioecological system principle for complementary sustainability dimensions integration.

5. Subsequently, the final main precondition is the integration precondition. After the fulfillment of all mentioned above sustainable mobility developments and the urban mobility governance design it should be purposely and carefully integrated into other municipality documents and processes, 
either mandatory/statutory or voluntary planning, and also integrated into the administration/governance system, especially not forgetting the municipal monitoring and reassessment steps.

\section{Acknowledgements}

A part of the research was carried out within the scope of the National Research Programme "Innovation and sustainable development: Latvia's post-crisis experience in a global context (SUSTINNO)" Project No.4. "Environmental Diversity and Sustainable Governance" (2015-2018).

\section{References}

[1] Rodrigue J.P. The geography of transport systems. Forth edition. New York: Routledge, 2017. $440 \mathrm{p}$.

[2] Chrader U., Fricke V., Doyle D., Thoresen V.W. (ed.). Enabling responsible living. Dordrecht: Springer, 2013. $179 \mathrm{p}$.

[3] Nieuwenhuijsen M., Urban and transport planning, environmental exposures and health-new concepts, methods and tools to improve health in cities. Environmental Health, issue 15, 2016, pp. $162-171$.

[4] Cervero R., Transport Infrastructure and the Environment: Sustainable Mobility and Urbanism. [online] [30.03.2019]. Available at: https://iurd.berkeley.edu/wp/2013-03.pdf

[5] Brizga J., Ernsteins R. Sustainable Consumption Governance Development in Latvia: Framework, Collaboration, Integration. Proceedings of the International Multidisciplinary Scientific Conferences on Social Sciences and Arts, April 6-0, 2016, Vienna, Austria, pp. 543-554.

[6] Szendrö1 G., Törö A. Theoretical investigation of environmental development pathways in the road transport sector in the European region. Transport, vol.29, 2014, pp. 12-14.

[7] European Commission White Paper on Transport "Roadmap to a Single European Transport Area - Towards a competitive and resource efficient transport system". [online] [30.03.2019]. Available at: https://eur-lex.europa.eu/legal-content/EN/ALL/?uri = CELEX:52011DC0144

[8] European Commission staff working document "The implementation of the 2011 "Roadmap to a Single European Transport Area - towards a competitive and resource-efficient transport system" five years after its publication: achievements and challenges". [online] [30.03.2019]. Available at: https://ec.europa.eu/transport/sites/transport/files/themes/strategies/doc/2011_white_paper/swd \% $282016 \% 29226 . p d f$

[9] Study of the European Parliament "Eco-efficient transport". [online] [30.03.2019]. Available at: http://www.europarl.europa.eu/RegData/etudes/etudes/join/2013/513520/IPOLJOIN_ET \%282013\%29513520_EN.pdf

[10]European Environment Agency. Environmental pressures from European consumption and production. Luxembourg: Publications Office of the European Union, 2013. 124 p.

[11] Schippl J. Assessing the desirability and feasibility of scenarios on eco-efficient transport: a heuristic for efficient stakeholder involvement during foresight processes. Foresight, vol. 18, 2016, pp. 41-58.

[12] Banister D., The sustainable mobility paradigm. Transport Policy, issue 15, 2008, pp. 73-80.

[13] Isaksson K., Antonson K., Eriksson L. Layering and parallel policy making - Complementary concepts for understanding implementation challenges related to sustainable mobility. Transport policy, vol. 53, 2017, pp. $50-57$.

[14] Krūkle Z., Ernšteins R., Brizga J. Sustainable mobility governance for urban municipalities in Latvia: social-ecological systems approach requirement and practice. Proceedings of the 17th International Multidisciplinary Scientific GeoConference SGEM 2017, June 29 - July 5, 2017, Alabena, Bulgaria, pp. 923-934.

[15] Krūkle Z., Bieziņa L., Pūgulis R., Ernšteins R. Municipal cycling governance developments in Latvia: instrumental complementarity precondition. Proceedings of the 5th International Multidisciplinary Scientific Conference on Social Sciences and Arts SGEM 2018. August 26 September 1, 2018, Alabena, Bulgaria, pp. 609-626. 
[16] European Commission guidelines "Developing and implementing a Sustainable urban mobility plan". [online] [30.03.2019]. Available at: http://www.eltis.org/sites/default/files/guidelinesdeveloping-and-implementing-a-sump_final_web_jan2014b.pdf

[17] Bojković N., Macura D., Pejčić-Tarle S., Bojović N. A Comparative Assessment of TransportSustainability in Central and Eastern European Countries with a Brief Reference to the Republic of Serbia. International Journal of Sustainable Transportation, vol. 5, 2011, pp. 319-344.

[18] Valmieras vides deklarācija. (Valmiera town Environmental declaration). (In Latvian). [online] [31.03.2012]. Available at: https://www.valmiera.lv/lv/valmieras_vides_deklaracija 